\title{
The seroprevalence of hepatitis B, hepatitis C and human immunodeficiency virus infections in paediatric oncology patients in Turkey
}

\author{
Semha Berberoğlu
}

\begin{abstract}
Summary
One hundred and two newly diagnosed children with malignancy followed up at the Pediatric Oncology Department of Ankara Oncology Hospital were investigated for hepatitis $B$, hepatitis $C$ and human immunodeficiency virus markers. The ages ranged between seven months and 17 years with a median of 10 years; 62 were male. Twenty-four patients had Hodgkin's disease, 11 had non-Hodgkin's lymphoma and 67 patients had other solid tumours. Four patients had positive HBsAg, 15 developed immunity against hepatitis $B$ and had anti-HBs antibodies. One patient had a previous infection with positive anti-HBc. Hepatitis $C$ virus antibodies were positive in only one patient. HIV serology was negative in all patients. These results show the high prevalence of hepatitis $B$ virus infection in paediatric oncology patients. In countries where hepatitis $B$ is endemic, strict screening of blood donors, usage of disposable equipment and vaccination of patients is recommended. Although the incidence of hepatitis $\mathbf{C}$ and human immunodeficiency virus infections are rising, infection with hepatitis $B$ is still by far the most common.
\end{abstract}

Keywords: hepatitis B virus, hepatitis C virus, human immunodeficiency virus, malignancy, children

Although technological advances have resulted in dramatic improvement in the survival rates of children with cancer, especially in developing countries, paediatric cancer patients are at an increased risk of viral infections. Unlike healthy individuals, these patients become highly contagious carriers of hepatitis B virus. Immunosuppressive therapy may increase the development of a chronic carrier state or the activation of latent infection may occur. ${ }^{1,2}$ Hepatitis $C$ virus is now the most commonly encountered blood-transmissible hepatitis infection among cancer patients. ${ }^{3}$ The incidence of human immunodeficiency virus (HIV) infection among children has increased dramatically, constituting $5 \%$ to $30 \%$ of all the cases of autoimmune deficiency syndrome (AIDS). ${ }^{4}$ The risk of transfusion-associated AIDS in multi-transfused patients is well known. ${ }^{5}$ This study was planned to investigate the seroprevalence of hepatitis $B$, hepatitis $C$ and HIV in a group of paediatric cancer patients treated in a state hospital in Ankara, Turkey, and to evaluate the need for prophylactic approaches.

\section{Materials and methods}

Blood samples were taken from 102 paediatric oncology patients, aged between seven months and 17 years (median 10 years), attending the Oncology Hospital in Ankara, Turkey, between July 1993 and December 1994. All the samples were taken at the beginning of therapy. The demographic characteristics of the study population are given in box 1. Patients' sera were tested for $\mathrm{HBs}-\mathrm{Ag}$, anti-HBs, anti-HBc IgG, anti-HBc IgM, anti-HCV and anti-HIV by enzyme-linked immunosorbent assay.

\section{Results}

The seropositivity for hepatitis $\mathrm{B}$ virus infection was $19.6 \%$. Incidence of $\mathrm{HBs}-\mathrm{Ag}$ positiv-

\begin{tabular}{|ll|}
\hline $\begin{array}{l}\text { Demographic characteristics of } \\
\text { patients (n=102) }\end{array}$ \\
\hline Age & \\
- median (years) & 10 \\
- age range & 7 months- \\
Sex (male/female) & 17 years \\
& $62 / 40$ \\
Types of tumours & $n$ \\
lymphoproliferative tumours: & \\
Hodgkin's disease & 24 \\
non-Hodgkin's lymphoma & 11 \\
non-lymphoproliferative tumours: \\
Ewing sarcoma & 15 \\
osteosarcoma & 10 \\
Wilms' tumour & 8 \\
rhabdomyosarcoma & 7 \\
neuroblastoma & 6 \\
soft tissue sarcoma & 4 \\
germ cell tumours & 3 \\
primitive neuroectodermal & 3 \\
$\quad$ tumours & \\
central nervous system & 3 \\
$\quad$ tumour & \\
primary liver tumours & 2 \\
nasopharyngeal carcinoma & 2 \\
Langerhans cell histiocytosis & 1 \\
optic glioma & 1 \\
thyroid carcinoma & 1 \\
unclassified & 1 \\
\hline
\end{tabular}

Pediatric Oncology Mesa Sedir Sok. 2/c, 06798 Ankara, Turkey 
ity was $4 \%$ and one patient had a previous infection with positive anti-HBc. Anti-hepatitis $\mathrm{C}$ virus seropositivity was $0.9 \%$. HIV contact was not found in any of the patients.

\section{Discussion}

Turkey is a developing country where hepatitis $B$ infection is still prevalent. In the general population HBs-Ag positivity is as high as 8$11 \% .{ }^{6-8}$ As paediatric oncologists, our problem is more serious than in other countries where the disease is seen less frequently. In a recent study screening the children seen in Hacettepe Children's Hospital, excluding those with liver disease, hepatitis B seropositivity was found to be $9.8 \%$ (HBs-Ag 5.4\%, anti-HBs $4.4 \%$ ). ${ }^{9}$ In a study conducted in early 1980 s from the same university, the incidence of hepatitis $B$ infection was $18 \%$ (HBs-Ag $2 \%$, anti-HBs $16 \%$ ) in previously untreated paediatric oncology patients but the incidence rose to $52 \%(37.7 \%$ positivity of $\mathrm{HBs}-\mathrm{Ag}$ ) in patients followed up for one year or more after diagnosis. ${ }^{10} \mathrm{~A}$ recent study conducted at the same institution of 1993 revealed better results. ${ }^{11}$ The incidence of hepatitis B infection was $13.8 \%$, and the HBs$\mathrm{Ag}$ carrier rate was $6.1 \%$. In a similar study conducted at Ege University in the Aegean part of Turkey, the HBs-Ag carrier rate was $9.4 \%$, while the hepatitis $B$ virus contact rate was $21.1 \%$ in 85 untreated paediatric oncology patients. ${ }^{12}$ Improvement of blood screening procedures and usage of disposable equipment for invasive diagnostic procedures may explain these better results. In a state hospital such as ours, the economic status of the patient population is lower than at the university hospitals. Patients come from less developed parts of Turkey, compared to those attending university hospitals and they have a higher risk of infection because of poor nutrition and poor hygiene. However, the incidence of hepatitis B infection was $19.6 \%$ while the HBs-Ag carrier rate was $4 \%$ in our study, so there was not a great difference between the two different social groups. The low socioeconomic and cultural status of our patients mean that they tend to be admitted to hospital at later stages of the disease. When they have active viral infections, it takes time to start anti-cancer therapy and this leads to progression of the malignancy. In the Hacettepe University Pediatric Oncology department, vaccination of newly diagnosed patients with a double dose of recombinant hepatitis $B$ vaccine was started in 1991. At 12 months seroconversion rate was found to be $70.5 \%$ using four different vaccines. ${ }^{13}$ In the light of these results, it can be concluded that vaccination should be given to all infants in the country.

Anti-hepatitis $\mathrm{C}$ antibody has been found in $80-100 \%$ of transfusion recipients who develop non-A, non-B hepatitis. ${ }^{3}$ Among cancer patients, hepatitis $C$ virus infection has gained in importance since it is now the most

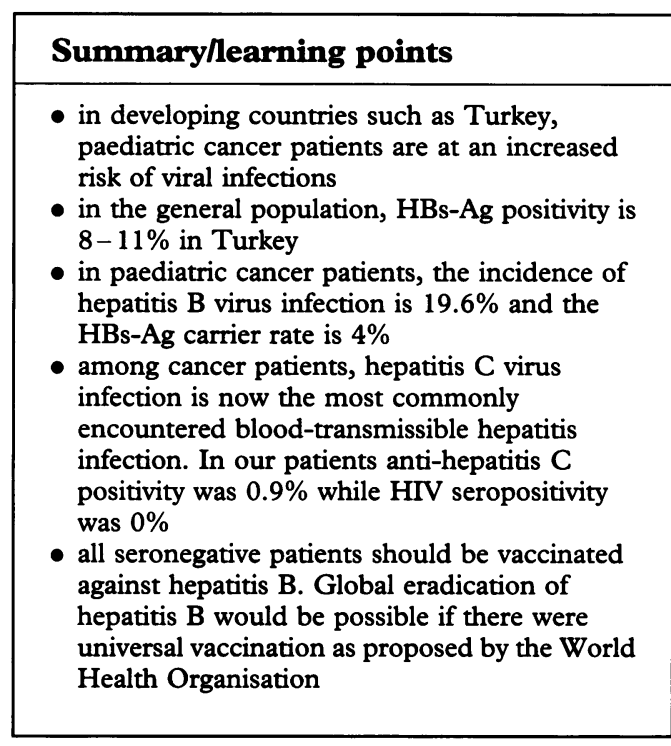

Box 2

commonly encountered blood-transmissible hepatitis infection. ${ }^{3}$ In a recent study from the Aegean part of Turkey, anti-hepatitis $C$ virus positivity was found to be $4.5 \%$ and $14.3 \%$ in paediatric patients with malignancy and in thalassemics, respectively. In healthy controls no hepatitis $C$ virus infection was observed. ${ }^{12}$ In our study anti-hepatitis $C$ virus positivity was $0.9 \%$. The difference may be due to the increased transfusion rate in the previous study where some of the patients were studied at the time of diagnosis and others during the chemotherapy period, having received multiple blood transfusions.

In a study conducted in Istanbul, Turkey, seropositivity for anti-HIV was $0 \%$ in the control group and $0.6 \%$ in the multi-transfused paediatric haematology or oncology patients. ${ }^{13}$ In multi-transfused patients the risk of transfusion-associated AIDS is well known. In our native blood donors, from whom al blood products are collected, the seroprevalence of HIV is low compared to European countries. ${ }^{14}$ This low level, and the $0 \%$ seropositivity seen in our patients, may be due to the predominant religion in our country. As a result, in our patient population, hepatitis $B$ virus infection is the most important, in contrast to more developed countries in which hepatitis $C$ virus and HIV infections are gaining more importance. Since it is currently considered good practice to offer HIV, hepatitis C and hepatitis B testing to all paediatric oncology patients in Turkey, routine usage of hepatitis B vaccination in seronegative paediatric haematology-oncology patients in Turkey at the time of diagnosis is an urgen need and should become government policy since the patient population is generally unable to afford vaccination. Although the price is high, the potential benefit of such an increased vaccination policy is considerable. 
1 Wands JR, Chura CM, Roll FJ, Maddrey W. Serial studies of hepatitis-associated antigen and antibody in patients receiving antitumor chemotherapy for myeloproliferative and lymphop $105-12$.

2 Entacher U, Jurgenssen O, Simbrurer G. Hepatitis B vaccination and immune response in children with malignant disease. Eur $\mathcal{F}$ Pediatr 1985; 144: 160-3.

3 Pizzo PA, Poplack DG. Principles and practices of pediatric oncology. 2nd edn, Philadelphia: JB Lippincott Co, 1993; p 1005.

4 Pizzo PA, Mueller BU. Pediatric AIDS. In: Pizzo PA, Poplack DG, eds. Principles and practice of pediatric oncology, Philadelphia: JB Lippincott Co, 1993; pp 939-47.

5 Fisher $M$. Transfusion associated acquired immunodeficiency syndrome - what's the risk? Pediatrics 1987; 79: 15660.

6 Çolakoğlu S Prevalence of $\mathrm{HBsAg}$ positivity in children and adults. (Turkish) Turkish Scientific Research Committee. Hepatitis Research Meeting, 1986, Ankara.

7 Soylu K, Uzunalimǒglu O, Sipahi N. HBV incidence in hospital workers. (Turkish) Turkish Scientific Research Committee Hepatitis Research Meeting, 1986, Ankara.
8 Pirnar A, Kanra T. Incidence and distribution of hepatitis Bs antigen in Turkey. Vox Sang 1976; 31: 67-9.

9 Uc A, Ozsoylu S. Age-prevalence of HBsAg positivity in children seen at Hacettepe Children's Hospital. $₹$ Turk Med Res 1992; 10: 264-6.

10 Akyol H, Sarialioğlu F, Büyükpamukçu M. Hepatitis B virus infection in pediatric cancer patients receiving anticancer chemotherapy. Turk f Cancer 1990; 20: 104-8.

11 Sarialioğlu F, Akyol $\mathrm{H}$, Büyükpamukçu $M$, Akyüz C Kutluk T. A therapeutic problem in pediatric oncology: the risk of $\mathrm{HBsAg}$ positivity at the time of diagnosis. Turk $\mathcal{f}$

12 Cancer 1993; 23: $27-33$. hepatitis-C, CMV and HIV markers in pediatric mepatitis-C, CMV and HIV markers in

13 Berberoğlu S, Büyükpamukçu M, Sarialioğlu F, Akyüz C, Berberoğlu $S$, Büyükpamukçu $M$, Sarialioğlu F, Akyüz C,
Ilhan I. Hepatitis B vaccination in children with cancer. Ilhan I. Hepatitis B vaccination in child

14 Yilmaz G. The distribution of HIV infected patients according to risk groups and the comparison of various serologic methods for detection of HIV. Thesis, Istanbul University School of Medicine, Turkey, 1989. 